\title{
Commercial Diplomacy and International Business: Inseparable Twins?
}

\author{
Huub J.M. Ruël, University of Twente, The Netherlands \\ Donna Lee, University of Birmingham, UK \\ Robin Visser, University of Twente, The Netherlands
}

The world economy is a dynamic environment full of opportunity and risk for international business. Such dynamism creates new political and economic space for the development of international business opportunities in fast developing economies including Brazil, China and India (Salmi \& Scott-Kennel, 2012), but it also increases economic risks for international businesses with investments in declining or even crisis ridden developed economies such as Greece. The dynamism is evident in the growth of new international businesses in the East such as Etihad (United Arab Emirates) as well as a new wave of developing country international business investments in the older economies of the West. Consider, for example, the 2010 purchase of the US food producer Keystone Foods by Brazilian firm Marfrig. This purchase is representative of the increasing tendency of fast developing country business acquisition (backed by their own governments) of major economic interests in the traditional sectors of the older economies (Benard, 2012). In many ways it is astonishing to consider that a Brazilian company now produces all of the meat in the MacDonalds burgers and Subway's sandwiches eaten by Americans. Similarly Tata Motor's purchase of Jaguar Land Rover from Ford Motors is further evidence of the new opportunities emerging economy businesses are exploiting in order to invest in the manufacturing sector in developed.

Navigating this dynamism successfully, competing in new and unknown markets while avoiding the risks inherent in familiar but now volatile markets, is crucial for new and old businesses and governments alike to ensure growth and even survival (Kalotay \& Filippov, 2009). The shift of economic opportunity from developed to developing economies means that international business has to navigate growth in economies where the formal regulatory and institutional context for doing business is very different from that which the business is used to and with often a very active role for the state. This is certainly the case with China and is a characteristic of the political economies of India, Brazil and Russia. It is in this context, the unfamiliarity of the political contexts of new market opportunities, that commercial diplomacy driven by close nation-state -business collaboration and diplomatic support for international business is needed and, moreover, that 'the need to expand and develop commercial diplomacy is all the more important' (Lee \& Ruël, 2012: xiv).
The idea that successful international business is just a matter of a clear business strategy and good business management is naïve and outdated. Benard's (2012) illustration of China's success in employing diplomatic means to secure a prime position in foreign markets for its businesses as opposed to the lack thereof in the USA is a recent and practical example of how diplomacy and business go hand in hand in this new political and economic environment.

In this short article we will call for more research on commercial diplomacy by international business scholars. We consider commercial diplomacy to be the work of a network of public and private actors who manage commercial relations using diplomatic channels and processes'. (Lee 2004: 51), implying a 'shift' in what diplomacy is. We will present a short description of what commercial diplomacy is and most importantly, how, from an international business point of view, research should be undertaken in terms of business-government communication as well as the organization and value creation process of commercial diplomacy.

\section{The Old and New Significance of Commercial Diplomacy}

To understand how commercial diplomacy and international business go hand in hand, one only needs to consider how trade and aspects of diplomacy have propelled civilizations into becoming great economic powers. From the Mesopotamians employing trade as an aspect of diplomacy and the Romans using trade to spread their culture even beyond the borders of the Roman Empire to Medieval times when English trade with the German Hanseatic League was supported by continuous diplomatic bargaining, trade and diplomacy have been closely related. In somewhat more recent times, the Dutch established an embassy in China in 1655 with the specific objective to improve trade and a new country called the USA would significantly change global economic and commercial relationships. A quite modern version of commercial diplomacy was adopted by the USA as Page (1902: 167-168) notes: 'through the principle of reciprocity she proposed to abolish exclusions, monopolies, and preferences, and thus to promote the advantages of both nations rather than "by outwitting the other" to secure some ex- 
clusive advantage for herself'. All in all, commercial diplomacy has in some sense been around for a considerable amount of time and the concept is nothing new.

\section{What is Commercial Diplomacy?}

Diplomacy typically involves information gathering, lobbying, advocacy, and the representation of interests in a negotiation. Commercial diplomacy involves all of these activities and focuses on negotiations around commercial deals. It is a multi-stakeholder activity involving public and private actors negotiating a business deal that will likely involve public as well as private commercial interests. A huge commercial deal such as the aforementioned Tata purchase of Jaguar Land Rover touches on the economic and political interests of the nation-state (it has implications for governance reputation as well as key economic indicators such as employment and GDP rates) as well as the reputation and economic development of the business. In order to capture such deals businesses often rely on the nation-state to provide commercial intelligence (information gathering) support (lobby for) and promote (advocacy) the business in both formal and informal negotiations in a variety of settings. In essence this often includes Ambassadors and foreign ministry staff organising and hosting trade fairs, but also includes direct lobbying on behalf of or accompanied by the CEOs or staff of businesses. From this, and the definitions that have been developed so far, Lee's definition of commercial diplomacy is an e pluribus unum one which states that commercial diplomacy is 'the work of a network of public and private actors who manage commercial relations using diplomatic channels and processes'. (Lee 2004: 51). This statement finds resonance in Lee \& Ruël (2012), who add to it by specifying public actors as nation-state and private actors as businesses operating in domestic, regional and systemic environments so satisfying both public and private needs.

There are plenty of reasons why public and private actors together can and should lead commercial diplomacy in new and unfamiliar markets and open up diplomatic networks for commercial reasons. First, embassy contacts generate economic intelligence that would have otherwise not been available. Second, diplomats are usually more visible in media and may thus draw attention (marketing) at relatively low costs. Third, diplomats usually have easier and influential access to high-level contacts than most businesses. Fourth, diplomats are usually seen as highly credible, making it easier to attract foreign direct investment. Fifth, intelligence gathered by foreign missions is centralized and this creates efficiencies for the sector; it keeps businesses from reinventing the wheel.

\section{Commercial Diplomacy at the Intersection of In- ternational Business and International Relations}

The definition given earlier shows how commercial diplomacy lies at the heart of the intersection of international relations and international business. As an integral component of entrepreneurial development it is key to economic success by providing governments and businesses with a means to interact within specific institutional settings so as to facilitate trade and investment growth. Using the diplomatic network, governments can highlight new markets and (inward) investment opportunities, and provide direct access to government (this is particularly significant where the state plays an interventionist role in the domestic market such as (hina) and business through the close links that diplomats have developed in their day to day jobs in overseas embassies. In so doing, commercial diplomacy combines the functions and interests of both government and business. They stimulate and reinforce each other: governments can strengthen political relationships by supporting entrepreneurship to and from home and host countries and international businesses are more likely to gain access to foreign markets if a foreign mission with a commercial presence is established in the host country. But the resource expenditure needs to go both ways (not least to satisfy public concerns about using public gains for private interests). Businesses will themselves need to commit resources and invest in developing personal relationships to react to, anticipate, and try to influence public decision making.

\section{How Effective is Commercial Diplomacy in Supporting International Business?}

Several quantitative assessments on the topic suggest that commercial diplomacy is effective. For example, Rose (2005) finds that bilateral exports rise by approximately 6-10\% for each additional consulate abroad. Wilkinson \& Brouthers (2000a; 2000b; 2006) come to much the same conclusions for specific activities such as trade shows and export promotion efforts. In addition, Ruël \& Zuidema (2012) show that commercial diplomacy is highly relevant and valuable in markets which are very different from the one at home. While helpful in highlighting that commercial diplomacy per se creates business growth, existing studies offer few if any insights into how to expand and develop this entrepreneurial activity beyond the obvious advantages to opening more overseas posts and organising more trade fairs from them.

In light of what we know and especially what we don't know, we argue that a research agenda needs to be set to elucidate the concept of commercial diplomacy. Three specific topics are of particular interest. First of all, the big picture (by which we mean the international and national context) in which commercial diplomacy takes place has hardly received any attention even though it is obviously a major influence on commercial diplomacy for nations, businesses and individuals. Second, we have an idea of specific activities of commercial diplomacy, such as trade missions and investment promotion, but what we don't have is an idea of how such activities are best organized and why a portfolio of activities is more adequate in some situations than others. Furthermore, at the individual level it is interesting to get a better understanding of how diplomats and business actors 'team up'together in pursuing business deals while at the same time serving public economic interests. What we do know of commercial diplomacy does not, unfortunately, constitute a very integrative understanding. We know bits and pieces

continued on page 16 


\section{continued from page 15}

of, for example, the commercial diplomat, government involvement in export promotion, the context of commercial diplomacy, the national commercial policy and specific activities of commercial diplomacy (e.g. trade shows and trade missions). If the need for an integrative approach wasn't clear already, it probably is by now. The first step in developing such an approach would be the development of a full set of commercial diplomacy instruments and an assessment of how they support or inhibit each other.

Such patchy knowledge could at the very least be strengthened by a thorough approach toward research. Alas, here too, we discern a small variety in research methods and a severe lack of comparative research. Most studies concern either specific case studies or the presentation of data. New models will need to be explored using relevant examples from international business studies and do so in the context of identifying links between the grand total of zero integrative views we have on commercial diplomacy.

Having an idea of the kind of perspective and scope future research to adopt is only half of the picture. Equally important is knowing what to actually investigate. Here, we advocate that based on what commercial diplomacy is and what we don't know yet, the adoption of an international business perspective would be very beneficial to both governments and businesses. To kick-start research, we would like to bring forth the following research questions to form a bridge between commercial diplomacy and international business. The first one of these is showing how the interaction between business and government takes place so as to point out effective means of communication and expectation management strategies for businesses. The second one is the manner in which governments and businesses can most effectively organize commercial diplomacy so as to facilitate the activities of businesses in foreign markets. The third one is the identification of the value creating process of commercial diplomacy so as to allow governments and businesses to recognize and benefit from mutual goals and practices.

\section{Concluding Remarks}

It is high time that we knew more about commercial diplomacy, which is defined as the work of a network of public and private actors who manage commercial relations using diplomatic channels and processes. Specifically, we need to know more about the complex interplay between governments and businesses, the organizational arrangement of commercial diplomacy and how value is created. This is to be done with reference to models and theories/insights from international business studies. Considering that the most urgent focus is on organization, communication and value, there is no way that international business can ignore commercial diplomacy any longer.

In this short article, we shared our view with you to raise a dialogue between those that study and practice international business and those that study and practice commercial diplomacy. To illustrate why this dialogue is needed, we need only point to Benard (2012: 101), who con- tends that 'the United States needs to find a happy medium in which business promotion again becomes a strong pillar of its foreign policy, although not its sole focus'. In a world where the USA is called upon to get its act together in terms of commercial diplomacy, it would be wise to provide insights to help decision-makers in businesses and governments design the most effective structures for commercial diplomacy to best support and enhance entrepreneurial activity.

\section{References}

Benard, A. 2012. How to succeed in business and why Washington should really try. Foreign Affairs, 91(4): 91-101.

Kalotay, K. \& Filippov, S. 2009. The global economic crisis and foreign subsidiaries in new EU member countries. AlB Insights, 9(3): 16-19.

Lee, D. (2004). The growing influence of business in U.K. diplomacy. International Studies Perspectives, 5: 50-54.

Lee, D. \& Ruël, H.J.M. 2012. Commercial diplomacy and international business: merging international business and international relations. In H.J.M. Ruël (Ed.), Commercial diplomacy and international business: a conceptual and empirical exploration: xiii - xix. Bingley, UK: Emerald Insight.

Page, T.W. 1902. The earlier commercial policy of the United States. The Journal of Political Economy, 10(2): 161-192.

Rose, A.K. 2005. The foreign service and foreign trade: embassies as export promotion. Working Paper 11111 National Bureau of ECOnomic Research, Cambridge, MA (USA).

Ruël, H.J.M. \& Zuidema, L. 2012. The effectiveness of commercial diplomacy: a survey among Dutch embassies and consulates. Discussion Papers in Diplomacy. http://www.clingendael.nl/ publications/2012/20120504_cling_research_artikel_discussionpaperindiplomacy_123_ruel_and_zuidema.pdf. Accessed 23 October 2012.

Salmi, A. \& Scott-Kennel, J. 2012. Just another BRIC in the wall? The rise of the BRICs and educating tomorrow's global managers. AIB Insights, 12(3): 3-6.

Wilkinson, T.J. \& Brouthers, L.E. 2000a. An evaluation of government sponsored promotion programs. Journal of Business Research, 47(3): 229-246.

Wilkinson, T.J. \& Brouthers, L.E. 2000b. Trade shows, trade missions and government governments: increasing FDI and high-tech exports. Journal of International Business Studies, 31 (4): 725-734.

Wilkinson, T.J. \& Brouthers, L.E. 2006. Trade promotion and SME export performance. International Business Review, 15: 233-252. 
Huub Ruël (h.j.m.ruel@utwente.nl) is a senior researcher of International Business at the University of Twente (The Netherlands). He holds a PhD in Business Administration from the University of Twente. Dr. Ruël's research interests include the intersection between commercial diplomacy and international business, electronic HRM in an international context and HRM in emerging economies. He has published many articles in these areas.

Donna Lee (d.lee.3@bham.ac.uk) is a Professor of International Organizations and Diplomacy at the University of Birmingham (U.K). She holds a PhD in International Political Economy from the University of Connecticut, USA. Her research interests include African economic diplomacy, WTO Trade negotiations, and the economic and commercial diplomacy of middle and emerging powers as well as small states. She has published widely in these areas and currently serves on numerous editorial boards.

Robin Visser (robinvisser@gmail.com) is a Junior Researcher at the University of Twente. He holds a BSc in Industrial Engineering \& Management and an MSc in Business Administration from the University of Twente. His research interest is commercial diplomacy and its connection with international business. He has (co) authored several articles in this area. 